\title{
Cultural Issues and Impacts of Software Process in Very Small Entities (VSEs)
}

\author{
Tatsuya Nonoyama ${ }^{1.2}$, Lian Wen'.2, Terry Rout', David Tuffley ${ }^{1.2}$, \\ Institute for Integrated and Intelligent Systems, Griffith University \\ ${ }^{2}$ School of Information and Communication Technology, Griffith University \\ 170 Kessels Rd, Qld 4111, Australia \\ $\{$ t.nonoyama, l.wen, t.rout, d.tuffley\}@griffith.edu.au
}

\begin{abstract}
ISO/IEC29110 is an international standard of software lifecycle for small software companies also known as Very Small Entities (VSEs). While VSEs come from a diversity of cultural backgrounds, the current ISO/IEC29110 for VSEs does not address these cultural variations. VSEs from various cultural backgrounds might therefore find it difficult to adapt such a standard. This paper raises the issue that the current ISO/IEC29110 should recognize the impacts of cultural variation on software processes and cultural suggestions. It also point out one cultural dimension has a significant impact on software processes and their efficacy. Furthermore, the concepts of cultural consideration should not be limited to regions but, also cover the management perspective of individual VSE. In this paper, we identified two opposite cultural types which affect their software processes significantly. We propose that to make software process standards more practical for VSEs from different cultural backgrounds.
\end{abstract}

Keywords: Organizational Culture, Cultural Diversity, Cultural Variation, Very Small Entities, Software Process, Software Standards and Cultural Dimensions,

\section{Introduction}

The successful adaption of ISO/IEC29110 has improved many small software companies over the years. The standard covers a variety of software processes and check lists to support the VSE. Prior in 2014, ISO/IEC15504 was too complex and expensive for small software companies to adapt (Abe, Troilo \& Batsaikhan, 2012). A light weight standard was specially built for small software companies also known as Very Small Entities (VSE). According to International Organizational for Standardization (ISO) classification of the VSE can be a project or a small company which consists of 25 or less employees (ISO/IEC29110, 2012: Laporte, Alexandre, \& Renault, 2008). 
However, not all VSEs has received the benefits from the current ISO/IEC29110. Some VSEs argue that ISO/IEC29110 do not adequately address the cultural backgrounds of the VSE. In fact, the standard is not compatible to fit their organizational cultures (Suryaningrum, 2012: Roldan, 2015). They are concerned that lack of cultural support in software process can impact on their software quality and the overall software capability.

The purpose of this paper is to strengthen the knowledge and information with regards to cultural issues of VSEs from different cultural backgrounds. The paper is not intended to address all aspects of cultural issues in VSE, only to address some aspects of cultural issues to provide closely tailored software process and management concepts for VSE with different cultural backgrounds. This paper is intended for ISO standard developers and researchers to help improve the efficiency of ISO/IEC standards. Regional differentiations between VSE are not significant enough to support compatibility of ISO/IEC29110.

The structure of this paper outlines below. The significance of the problem highlights the importance that made cultural suggestions has the potential to improve the overall software capability of the VSE. The research question of this paper is divided into two important objectives to tackle the complex phenomenon of VSE's cultural background. Furthermore, in the literature review, we have selected a particular cultural dimension from Geert Hofstede's work. The cultural element of "Individualist VS Collectivist" was analyzed for addressing the research question.

The outcomes of the paper include a table that defines the characteristics of each VSE depending on their management perspective styles. Based on the six cultural dimensions framework, we have proposed tailor made cultural suggestions. The discussion, explains VSE's cultural backgrounds can have overlapping issues as well as expected outcome for applying the cultural suggestions. In conclusion, the paper recaps on how cultural suggestions can benefit ISO/IEC developers and researchers then briefly discusses future direction of this paper.

It is important for ISO/IEC standards developers and researchers to understand the complex cultural backgrounds of software development across the regions. Norbury (2003) argues that, the cultural backgrounds between VSE are different as well as across the regions (Western countries and Asian countries). Furthermore, the organizational culture highly impacts on the way people adapt new organizational culture, software processes and management concepts. Our cultural suggestion could be applied to small medium enterprises (SMEs) with minor modifications to fit the characteristic trends of VSEs.

\section{Literature Review}

In this section, we investigated several literature studies in relations to culture and software process. The literature review covers the background information of software standards. Furthermore, we explored the cultural dimensions framework by Geert Hofstede. The key research question of this paper is: how does cultural diversity / issues effect on VSE's implementation? The paper then divides the key 
question into two objectives. Objective 1: what are the cultural issues among VSE when adapting software processes? Objective 2: how does the VSE's organizational culture impact on the content of software processes? We understand that all VSEs require adjustments to the software processes from ISO/IEC29110 to meet their cultural backgrounds.

Every VSE has different ways to manage software processes, software quality and people. The feasibility to adapt ISO/IEC29110 is dependent upon VSE's cultural backgrounds (Nonoyama, Wen and Rout, 2016). Despite the fact that the current ISO/IEC29110 provides technical support to improve software capability, however, it does not fully address cultural variation in VSEs. It is important to address cultural backgrounds to help individual VSE to adapt. Furthermore, the standard should include cultural suggestions to resolve the VSE's cultural issues. These cultural issues include management perspective styles, work conditions and organizational culture. Facing these cultural issues not only impacts on the standard compatibility but, also creates a serious financial issue in a long term. Although, these cultural issues are not limited to VSEs, the size of software companies increases the complexity of adapting ISO standards in general. This is the reason why we need to acknowledge the various cultural backgrounds of VSEs. In comparison to larger scale companies such as SMEs, VSEs with strong cultural backgrounds tends to have their own traditional (native) approach in software development.

\subsection{Software Standards for VSEs}

In 2011, International for Standardization Organization (ISO) and International Electrotechnical Commission has published a set of standard called ISO/IEC29110. ISO/IEC 29110 provides a variety of profiles for VSEs. The standard was deployed only the relevant software processes from the original software standard called ISO/IEC 12207. The purpose of ISO/IEC29110 is to facilitate measurable and tangible benefits to the clients through the expected outcomes (Wen and Rout, 2012). To help the VSE to satisfy the expected outcomes, it offers the guideline for establishing appropriate software processes (Nonoyama, Wen and Rout, 2016). The potential benefit in ISO/IEC29110 is that VSEs can establish more consistent and tailored software processes to improve their software capability level.

\subsection{Hofstede's Cultural Dimensions Framework}

We first analyze national culture then we narrow it down into the organizational culture of the VSE. The six cultural dimensions framework by Geert Hofstede is a good starting point to understand national culture and the impacts of software processes. The purpose of cultural dimensions framework is to provide comprehensive knowledge of how values in the workplace are influenced by national culture (Hofstede, 1984). In order to understand VSE's organizational cultures, it is important to understand the values of national cultures. The framework also suggests that the organizational culture and the national culture should not be separated or cannot be separated. Sordo (2015) argue that Hofstede's cultural dimension 
framework provides a strong linkage between the national culture and the organizational culture. In this paper, we also want to stress that cultural variation in individualist and collectivist have some similarities in the context of software development.

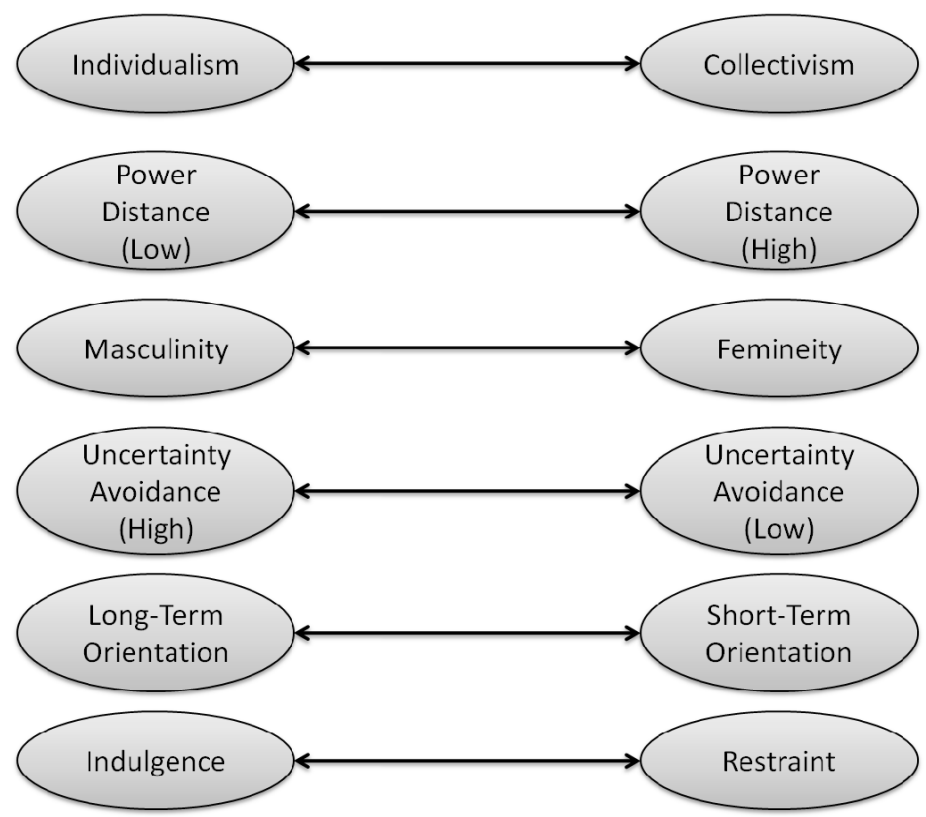

Figure 1. Hofstede's Cultural Dimensions Framework (Hofstede, 1984: Sordo, 2015).

In figure 1, presents the latest version of Hofstede's cultural dimensions framework. In the original framework, it only presented five cultural dimensions. A new dimension called "Indulgence VS Restraint" was introduced in the recent studies (Sordo, 2015). A new cultural dimension is included in Figure 1.

We have highlighted one relevant cultural dimension which closely relates to organizational culture in VSEs. The cultural dimension of "Collectivist VS Individualist" shows a significant reflection on how VSE manage and adapt software process (Gordon and O'Connor, 2015). Adaptation of software process differs based on the dominant management perspective of the VSE.

\subsection{Collectivist VS Individualist}

In collectivist culture, the group work and group cohesion are highly valued. It is important for collectivist culture to belong to a particular group or community (Hofstede, 1984). This also applies to VSE and their software processes. The software process includes a large amount of communications and interactions. Furthermore, 
employees are expected to cooperate in creating harmony between workers and clients (Suryaningrum, 2012). As the result, collectivist culture VSE has slower software process time compared to the VSE with individualist culture. The software contracts and goals are negotiable depending on the client's organizational status.

On the other hand, VSE with individualist culture highly values individual's expertise and experience. They primary show interests on close relatives and friends more than a strong connection towards a particular organization or community (Hofstede, 1984). Additionally, the organizational status is not the first thing to be considered. Instead, they consider organizational policies and software capability level at initial stage of software development (Laporte, Alexandre \& Renault, 2008). VSE with individual culture, have a clear relationship between clients and employees. The client communication should only be work related matters. In collectivist environment, communication needs to be on personal level (Suryaningrum, 2012). However, this rarely occurs in the context of individualist culture.

For example: Japanese and Chinese VSEs are generally viewed as collectivist culture. They prefer to have longer software process which closely aligns with their guidance of team work management (management by passion) (Norbury, 2003: Coleman and Basten, 2015). America is a commonly used example of individualist culture. American based VSE are viewed as individualist culture when developing software. It is also known as task based management with clear individual objectives (Sordo, 2015). Therefore, software development time is relatively shorter than the VSE in collectivist culture.

However, not all countries have the clear boundary between national culture and organizational culture. Another example is: Taiwan and Hong Kong generally do not share Chinese collectivist culture. The organizational cultures in Taiwan and Hong Kong are much more diverse than the mainland China. According to Norbury (2003), Roldan (2015), Saith (2008) and Sordo (2015) the organizational cultures in Hong Kong and Taiwan are categorized as individualist culture whereas in China, collectivist culture is dominant in both national culture and organizational culture. Some argue that, places such as Hong Kong and Taiwan still resembles Chinese collectivist culture which shows a strong cultural association with the mainland China.

\section{Cultural Suggestions}

\subsection{Characteristics of Management Perspective Styles}

This section highlights the differences between two management perspective styles in VSEs. According to Table 1, some characteristics are overlapping each other. The table also shows some correlations from individualist and collectivist cultures which reflects on their organizational culture. However, as mentioned in section 2.3, in some cases, the national culture do not reflect on how people do their businesses (organizational culture). This obviously impacts on software processes and software development in VSEs. 
The purpose of Table 1 is to compare two management perspective styles "Task based and Team work based managements which commonly witnessed across the VSE's cultural backgrounds. The characteristic of work culture indicated the major difference in prioritizing goals and objectives (Clarke and O'Connor, 2011: Nonoyama et al, 2016). Furthermore, task based management corresponded higher importance on archiving individual and organizational achievements. Team work management on the other hand, is focused on their organizational goals and objectives. The cultural backgrounds are differentiated and measured as characteristics 1.1 to 1.5 . Detailed information of each characteristic element is presented below Table 1 .

Table 1. Comparisons of Task Based and Team Work Management Perspective Styles

\begin{tabular}{|c|c|c|}
\hline Characteristic Element & Task Based Management & Team Work Management \\
\hline $\begin{array}{l}1.1 \\
\text { Working Hours }\end{array}$ & $\begin{array}{l}\text { Over time work is not } \\
\text { acceptable. Acceptable in } \\
\text { emergencies. }\end{array}$ & $\begin{array}{l}\text { Over time work is generally } \\
\text { accepted. }\end{array}$ \\
\hline $\begin{array}{l}1.2 \\
\text { Working Conditions }\end{array}$ & $\begin{array}{l}\text { Work conditions are clearly } \\
\text { established. }\end{array}$ & $\begin{array}{l}\text { Work conditions are clearly } \\
\text { established }\end{array}$ \\
\hline $\begin{array}{l}1.3 \\
\text { Work Culture }\end{array}$ & Clear objectives and goals. & $\begin{array}{l}\text { Objectives and goals are } \\
\text { changeable depending on the } \\
\text { clients and senior employees. }\end{array}$ \\
\hline $\begin{array}{l}1.4 \\
\text { Communications }\end{array}$ & Direct approach. & Indirect approach. \\
\hline 1.5 & Clearly defined. & Clearly defined. \\
\hline Roles \& Responsibilities & $\begin{array}{l}\text { Task allocation should not } \\
\text { change. }\end{array}$ & Task allocation is changeable. \\
\hline
\end{tabular}

(Norbury, 2003: Nonoyama et al, 2016: Perlow, 2001: Laporte, et al, 2008: Roldan, 2015).

\subsection{Working Hours}

Different management perspective has different work hours at workplace. Generally, task based management do not accept over time work unless it is an emergency (Perlow, 2001). On the other hand, team work management tends to accept longer hours of commitment in general.

\subsection{Work Conditions}

The work conditions are established in both management perspective styles. Based on the work policy, the average work hour is 40-45 hours (Perlow, 2001: Norbury, 2003). In some cases, employees were told to work more than 45 hours per week to catch up 
with clients. This is common in team work management environment where employees were obligated to entertain clients or work overtime.

\subsection{Work Culture}

Task based management generally prefers to have clear goals, objectives and justifications. Furthermore, in task based management, shows higher importance on individual objectives and goals (Roldan, 2015). Whereas in team work management, they consider their organizational goals and objectives are the most important aspects in the project (Norbury, 2003). Another important aspect in team work management is that clients and senior employees have more power to influence on software development.

\subsection{Communications}

Direct approach is common in task based management environment. The client communication is crucial yet, only performed for business purposes (Sordo, 2015). In comparison to task based management, team work management tends to interact and communicate frequently to the clients. In some cases, it is a norm to entertain high profile clients outside of work hours (Norbury, 2003). For team work management, indirect communication is considered a formal approach to understand clients on the personal level.

\subsection{Roles \& Responsibilities}

Task based management establish clear roles and responsibilities of each employee. Organizations (VSEs) are expected to accomplish individual tasks. Employees from task based management environment do not expect to accomplish tasks from outside of their boundaries (Roldan, 2015: Laporte, et al, 2008). However, in team work management environment, all employees are expected work towards their organizational goals. The boundary between delegated tasks and additional (external) tasks are not clearly outlined. In other words, employee's expertise and knowledge are frequently shared among other employees to accomplish the project.

\subsection{Software Process Impacts in Two Cultural Types}

Based on the literature review, it would be desirable to differentiate suggestions based on the dominant management perspective of the VSE. Providing suggestions based upon the regional segregation is too general and insufficient. Instead, the VSE's cultural backgrounds should determine the content of cultural suggestions.

The purpose of this table 2 is to determine the software process impacts between individualist culture and Collectivist culture. We have separated the VSE's cultural backgrounds into two cultural types A and B. The cultural type A: as individualist and cultural type B as collectivist. It is highly recommended for ISO/IEC developers and 
researchers to acknowledge these characteristic elements for future improvements. Both suggestions include the basic concepts to select a suitable software process that fits their cultural backgrounds.

Table 2. The Comparisons of Individualist Culture and Collectivist Culture

\begin{tabular}{|l|l|l|}
\hline Impact Element & $\begin{array}{l}\text { Cultural Type A } \\
\text { (Individualist) }\end{array}$ & $\begin{array}{l}\text { Cultural Type B } \\
\text { (Collectivist) }\end{array}$ \\
\hline $\begin{array}{l}\text { Management } \\
\text { Perspective }\end{array}$ & Task based. & $\begin{array}{l}\text { Team work. } \\
\text { (Management by passion) }\end{array}$ \\
\hline $\begin{array}{l}\text { 2.2) } \\
\text { Adaption of Software } \\
\text { Process }\end{array}$ & $\begin{array}{l}\text { A detailed plan, objectives and } \\
\text { goals. }\end{array}$ & $\begin{array}{l}\text { Flexible plans to prepare for client } \\
\text { expectations. } \\
\text { (Slow paced decisions) }\end{array}$ \\
\hline $\begin{array}{l}\text { (Fast paced decisions) } \\
\text { Software Process } \\
\text { Choice }\end{array}$ & Fast paced. & Slow paced. \\
\hline Country Example & U.S. and Hong Kong & Japan and India. \\
\hline
\end{tabular}

(Sharp, Hovenden and Woodman, 1998: Perlow, 2001: Sordo, 2015).

\subsection{Characteristics of Cultural Type A: Individualist}

A certain culture type preferred their goals and objectives to be clearly defined. In this type of VSE, an employee dislikes the ambiguity when adapting software process and development. VSE with individualist culture would expect their software process to be well organized with a clear justification. Furthermore, VSEs with individualist culture are less likely to seek support compared to collectivist culture based VSEs. This is because; individual expertise and knowledge are highly valued. Team work and common work culture are still important yet; the individual differences are accepted in the individualist culture (Perlow, 2001: Sharp, et al, 1998). In order to increase consistency in software development, they tend to discuss roles \& responsibilities. VSEs with individualist culture preferred to keep the client communications / interactions to the (basic) minimum.

Unlike collectivist culture based VSEs, individualist culture based VSEs tends to overly eliminates slacks including (social interactions and client communications). The elimination of slacks highly impacts on the software process time. Depending on the content of slack, it can be a positive or negative outcome (Sordo, 2015). It is always important for individualist VSEs to carefully consider eliminating client interaction / communication slacks.

Additionally, clear relationship boundary between clients and employees. A moderate amount of direct communication can help to maintain the harmony between 
client and employee. VSEs with individualist culture have equal bargain power between client and employee. Both employees and clients are entitled to openly discuss their concerns. It is also common in individualist culture to respect each other's privacy (a personal life and non-work related matters) and keep it to the minimum.

\subsection{Cultural Suggestions for Cultural Type A: Individualist}

Based on these characteristic elements, VSE with cultural type A, it is highly recommended to apply these suggestions.

1. Increase interaction and communication level among clients and other fellow employees in the VSE. Show some acknowledgment of different opinions, expertise and organizational culture.

2. Learn to adjust communication approach based on the VSE / clients. Direct approach and communication can be inappropriate in some cultures or the VSE's organizational culture. In the initial stages of a project, indirectly communicate with clients. Once the harmony was created, establish clear and direct communications with clients.

3. Avoid focusing only on technical issues in the VSE (poor coding, management concepts and testing procedures). Non-technical or cultural issues (incompatibility of standards) are equally important to be resolved.

\subsection{Characteristics of Cultural Type B: Collectivist}

VSEs with cultural type B generally accept the ambiguities during the software process and development. It is acceptable and norms to work over time. Team work engagement and common shared beliefs are the primary traits of collectivist culture. Therefore, a software process is necessary to handle a large communication / interaction management.

A large volume of communications and interactions are frequently take place during the software development. A frequent communication helps the VSE to polishing up the details of software and client expectations. However, in some scenarios, an excessive amount of communication can be a disaster (Norbury, 2003). The confusions between clients and employees can impact on the quality of software process and development.

Another important characteristic of collectivist culture is that social engagement is very common among employees and high profile clients. Most of these client engagement and entertainment occurred outside of work hours (Suryaningrum, 2012). As the results of these client engagement and communication, the software process time becomes slower than individualist culture A. Detailing out client requirements and expectations can be time consuming. Additionally, a frequent change in software 
goals and objectives can dramatically slow down the overall software process (Yan and $\mathrm{Li}, 2015$ ). A large volume of client communications and interactions make the software process more complex to be adapted.

\subsection{Cultural Suggestions for Cultural Type B: Collectivist}

Based on these characteristic elements, VSE with cultural type B, it is highly recommended to apply these suggestions.

1. Minimize communications between employees and clients. Time management concept is needed to help the VSE to minimize the volume of communication and interactions with clients.

2. Improve individual expertise and knowledge of employees. It is important to provide practical guideline to train employees to be more independent. Ensure to provide potential benefits of implementing software processes.

3. Focus more on technical side of software process and software development. It is important to highlight the importance of establishing clear objectives and goals can reach out international audience.

\section{Discussion}

Major challenge of this paper is tackling the questions that associate with cultural issues. As mentioned before, some VSE's cultural backgrounds may overlap between individualist culture and collectivist culture. The effect of these suggestions can be time consuming and can pose risks for some VSEs. It is also worth highlighting the point that, a close alignment between ISO/IEC29110 and VSEs may be limited to a certain cultural backgrounds. Having the basic suggestions could only reduce the complexity of cultural issues. It may not be sufficient to fully understand the cultural backgrounds of VSEs. In other words, a new set of standard may be needed to convince the VSE for adapting software processes.

The literature review indicated that work condition of the VSE was standardized. Both cultural types were exposed in similar work hour conditions. In the cultural suggestions section, the table 1 and 2 are useful to gain knowledge in management differences and the organizational cultures of the VSE. Both cultural types also indicated some overlapping characteristic elements (Coleman and Basten, 2015). In other words, both culture types could improve on a particular characteristic element. There is no clear boundary between VSE's cultures including cultural issues and management perspective styles.

The expected outcome of this paper is to reduce the cultural incompatibility when adapting ISO/IEC29110. For VSEs with cultural issues, these suggestions should facilitate in adapting more stable and suitable software process in place. Acknowledgment on cultural backgrounds could motivate VSEs to adapt 
ISO/IEC29110. It is important for ISO/IEC standard developers and researchers to understand different cultural backgrounds can impact on the adaptations of software processes.

The suggestions for both cultural types are designed to save resources and software reworks during the software development. It should also clarify the VSE to adapt which software process features would benefit them. For cultural type A tends to reflects on the characteristic element of task based management perspective style. In this cultural background, employees are expected to be independent and the overall software process become faster than collectivist culture based VSEs. On the other hand, collectivist VSEs has a strong relation to team work based management perspective style. This also indicated that collectivist VSEs should shorten the software process time by reducing the amount of client communication and interaction. We would like to highlight that these suggestions can facilitate a closer alignment between the concepts of ISO/IEC29110 and VSE's cultural backgrounds.

Furthermore, our suggestions can be enhanced to fit the characteristics / situational factors of larger scale software companies. It would be important to investigate the organizational cultures of SMEs and redesign the differences to tailor the software process for SME's audience group. Since SMEs may have higher resistance for change than VSEs with 25 employees or less (ISO/IEC29110, 2011). The major difference between VSEs and SMEs is the size of the software company. In other words, the number of employees can impact on the software capability, software development costs and the organizational culture.

\section{Conclusion}

We have concluded that the cultural backgrounds should not be determined by geographical regions of the VSE alone. The VSE's cultural background should be analyzed based on their work hours, work culture and management perspective styles. Therefore, the generic ISO/IEC29110 is not sufficient to address the VSE's cultural backgrounds and their cultural issues. It is important for standard developers and researchers to understand the national cultures of the VSE as well as the generic trends of organizational culture. We consider these cultural suggestions would help the current ISO/IEC29110 to more feasible for VSEs with strong cultural backgrounds. The paper highlights that acknowledgment in cultural backgrounds will help ISO standard developers to suggest tailor made software processes for VSEs. Based on our literature review, the organizational cultures in different regions of VSEs were different yet; some overlaps between cultural types. In addition, some characteristics in VSEs can overlap with SME's cultural backgrounds.

In this paper, we want to stress that determining the national cultures of the VSE would be the initial stage to gain the basic knowledge in the VSE's organizational cultures. We have provided Hofstede's cultural dimension frameworks to link the cultural impacts and the VSE's characteristic trends. The paper narrowed it down the national culture and applied to organizational cultures of the VSE. The comparison 
table of task based management and team work based Management (Table 1) was developed to highlight the major differences in VSEs.

Based on the findings of literature review, we have proposed a table 1 for two management perspective styles. In this paper, we linked these perspective styles with two cultural types. Cultural type A includes the major characteristic of task based management perspective style. On the other hand, cultural type B, resembled as a team work management perspective style.

Furthermore, we have developed a Table 2 which consists of cultural suggestions for VSEs. The suggestions are tailored into cultural type A based VSEs and B as collectivist based VSEs. The cultural type A indicated that the overall software process should be designed to spend more time and resources on client interactions. The overall process may become slower yet, capable to capture greater details of client requests. As the results, it would gradually sustain the balance between client requirements and software requirements. On the other hand, the cultural type B should focus on the technical side of software process. In other words, the software process should be designed to reduce a large amount of communications. It is highly recommended to design the software process with a basic management concept to clarify goals and software objectives. It is also important to eliminate unnecessary slacks including any unnecessary client entertainment and over communicating clients on the personal level. The Cultural type B should spend more time and resources to establish more consistent software processes.

Our future research would involve strengthening the knowledge in the VSE's national culture and the organizational culture. This is important for our future works because, we can develop more detailed suggestions to help ISO/IEC29110 for more specific to resolve cultural diversity. This includes enhancing our cultural suggestions towards SMEs as well. We would also want to stress that, the future work should address the following challenges. The first challenge was related to the cultural linkage between Hofstede's cultural dimension frameworks and the concepts of software processes and software development. The frameworks were originally adopted for addressing the national culture between different countries. Having said that, we needed to find the evidence to suggest that cultural factor highly affects the way people adapt software processes. The second challenge was related to analyzing the frameworks of Geert Hofstede. It was particularly difficult to select which cultural dimension had a strong impact on the characteristics of the VSE. Each dimension has more or less impacts on their software development yet; requires time-consuming research studies. Lastly, addressing these challenges would help align current ISO/IEC29110 to be more practical and relevant for VSEs with compatibly concerns and other cultural issues.

\section{References}

1. Abe, M., Troilo, M. \& Batsaikhan, O. (2012). Financing Small and Medium Enterprises in Asia and the Pacific. Journal of Entrepreneurship and Public Policy, 4 (1), 2-32 
2. Coleman, D. \& Basten, S. (2015). The Death of the West: An alternative view. Population Investigation Committee, 69 (1), 107-118.

3. Clarke, P. \& O'Connor, R. V. (2011). The Situational Factors that Affect the Software Development Process: Towards a Comprehensive Reference Framework. Information and Software Technology, 54 (5), 433-447.

4. Gordon, M. S. \& O'Connor, R. V. (2015). Understanding the Gap between Software Process Practices and Actual Practice in Very Small Companies. Software Qual J, 9282 (6), 1-22.

5. Hofstede, G. (1984). The Cultural Relativity of the Quality of Life Concept. Academy of Management, 9 (3), 389-398.

6. ISO/IEC TR 29110-5-1-2:2011 -Software engineering -- Lifecycle profiles for Very Small Entities (VSEs) -- Part 5-1-2: Management and engineering guide: Generic profile group: Basic profile

7. Laporte, C. Y., Alexandre, S. \& Renault, A. (2008). Developing International Standards for Very Small Enterprises. Willowdale: IEEE Computer Society.

8. Norbury, P. (2003). A Traveller's Guide to Custom and Culture. Kuperard: Graphic Arts Center.

9. Perlow, L. A (2001). Time to Coordinate Toward an Understanding of WorkTime Standards and Norms in a Multicountry Study of Software Engineers. SAGE Journals, 28 (1), 91-111.

10. Roldan, M. D. (2015). Sustaining "Lilliputs" in the Global KnowledgeBased Economy: Prospects for Micro, Small, and MediumScale Enterprises in the Developing World. European Journal of Sustainable Development, 4 (2), 269-274.

11. Nonoyama, T., Wen, L. \& Rout, T. (2016). Current Challenges and Proposed Software Improvement Process for VSEs in Developing Countries. Communications in Computer and Information Science, 609 437-444.

12. Saith, A. (2008). China and India: The Institutional Roots of Differential Performance. Institute of Social Studies, 39 (5), 723-757.

13. Sharp, H.C., Hovenden, F.M. and Woodman, M. (1998). Factors Affecting the Adoption and Evolution of Software Quality Management Systems, Computing Department, the Open University, Technical Report TR 98/17.

14. Sordo, A. I. \& (2015). Beyond Hofstede's Cultural Dimensions Theory: Approaching a Multicultural Audience. Retrieved May 26, 2017 from Skyword, Web site: https://www.skyword.com/contentstandard/marketing/beyond-hofstedescultural-dimensions-theory-approaching-a-multicultural-audience

15. Suryaningrum, D. H. (2012). Knowledge Management and Performance of Small and Medium Entities in Indonesia. International Journal of Innovation, Management and Technology, 3 (1), 35-41. 
16. Wen, L. \& Rout, T. (2012). Using Composition Trees to Validate an Entry Profile of Software Engineering Lifecycle Profiles for Very Small Entities (VSEs). Communications in Computer and Information Science, 290 38-50.

17. Yan, H. \& Li, Y. (2015). Research on the Relationship of Government subsidies and Enterprise performance. 3rd International Conference on Management, Education, Information and Control, p.1806. 